Revista Española de Antropología Americana ISSN: 0556-6533

https://doi.org/10.5209/REAA.61969

\title{
Plazas, ushnus y experiencias rituales en el valle Calchaquí Norte durante la ocupación inka
}

\author{
Alejandro Ferrari ${ }^{1}$, Félix Acuto ${ }^{2}$, Joaquín Izaguirre ${ }^{3}$ y Cristian Jacob ${ }^{4}$
}

Recibido: 13 de abril de 2016 / Aceptado: 4 de diciembre de 2016

Resumen. En este trabajo discutimos el modo en que los inkas utilizaron la arquitectura de sus asentamientos y la topografía circundante para manipular las experiencias somáticas de quienes participaban en eventos público-ceremoniales. Para ello discutimos la disposición espacial y material de cuatro sitios localizados en el valle Calchaquí Norte (provincia de Salta, Argentina); dos sitios de altura ubicados en la zona de los Nevados de Cachi y dos asentamientos en las áreas septentrional y meridional de esta sección del valle. Nos concentraremos tanto en las estructuras y rasgos presentes en estos cuatro sitios así como en las movilidades y vistas incentivadas por su configuración espacial. Haremos especial énfasis en la accesibilidad visual y física a los espacios de congregación, en las vistas promovidas e inhibidas por su arquitectura, y en la presencia de estructuras y rasgos íntimamente relacionados al ceremonialismo andino como ser plataformas, canales, wank'as, y monolitos. Argumentaremos que las plazas y plataformas de estos asentamientos no solo fomentaban una clara distinción entre representantes del Tawantinsuyu y representantes locales, sino que además dejaban en claro la competencia distintiva y la posición privilegiada que tenían los primeros a la hora de comunicarse con ciertas entidades no humanas del paisaje andino.

Palabras clave: Arquitectura inka, eventos público-ceremoniales, experiencias rituales.

\section{[en] Plazas, Ushnus, and Ritual Experiences in the North Calchaquí Valley during Inka Occupation}

\begin{abstract}
This paper discusses how the Inkas used the architecture and the surrounding topography of their settlements to manipulate peoples' somatic experiences during public ceremonial events. Therefore, we discuss the material and spatial arrangements of four Inka settlements located in the North Calchaquí Valley (Salta Province, Argentina); two high altitude settlements located in the Nevados de Cachi area and two sites located in the northern and southern areas of this portion of the valley. We will focus on the movements and views encouraged by the location and spatial configuration of certain buildings and traits within these sites. We will emphasize the visual and physical accessibility of congregation spaces, the sights offered by their architecture and layout design, and the presence of other devices intimately related with Andean ceremonialism such as platforms, channels, wank'as, and monoliths. We will argue that the Inkas not only sought to clearly differentiate themselves from the locals, but also to make clear their distinctive proficiency and privileged position to communicate with certain non-human entities of the Andean landscape.
\end{abstract}

Keywords: Inka architecture, public ceremonial events, ritual experiences.

\footnotetext{
CONICET y Universidad Austral. alejandroferra@gmail.com

IMHICIHU-CONICET y Universidad Nacional de La Matanza. facuto@gmail.com

Universidad de Buenos Aires, Facultad de Filosofía y Letras. joaquin.izaguirre@gmail.com

4 zamapurro@yahoo.com.ar
} 
Sumario. 1. Colonialismo inka en el valle Calchaquí Norte: nuevos lugares, nuevos paisajes, nuevas narrativas. 2. Espacios públicos y plataformas ceremoniales. 3. Los inkas en la periferia del paisaje local: el caso del sitio Cortaderas 4. Los inkas en la cotidianeidad local: el caso de La Paya/Guitián. 5. Construyendo y habitando en el territorio del cerro: los sitios El Apunao y Uña Tambo. 6. Discusión y conclusiones. 7. Referencias.

\section{Colonialismo inka en el valle Calchaquí Norte: nuevos lugares, nuevos paisa- jes, nuevas narrativas}

$\mathrm{Al}$ arribar y asentarse en el área septentrional del valle Calchaquí (Salta, Argentina), los inkas desplegaron una ocupación selectiva y no homogénea del paisaje. En este caso, la ocupación inka estuvo enfocada en tres áreas específicas del territorio (Figura 1). En cada una de ellas, a través de la infraestructura instalada, los lugares construidos y los sentidos investidos, el Tawantinsuyu propuso una relación específica con la población local y con el entorno natural y las entidades sagradas no humanas que lo habitaban.

Por un lado, los inkas decidieron concentrar sus principales asentamientos en un sector de la región que se encontraba alejado de los focos de ocupación local. Este rincón del paisaje nor-calchaquí, hacia su extremo noreste se encontraba práctica-

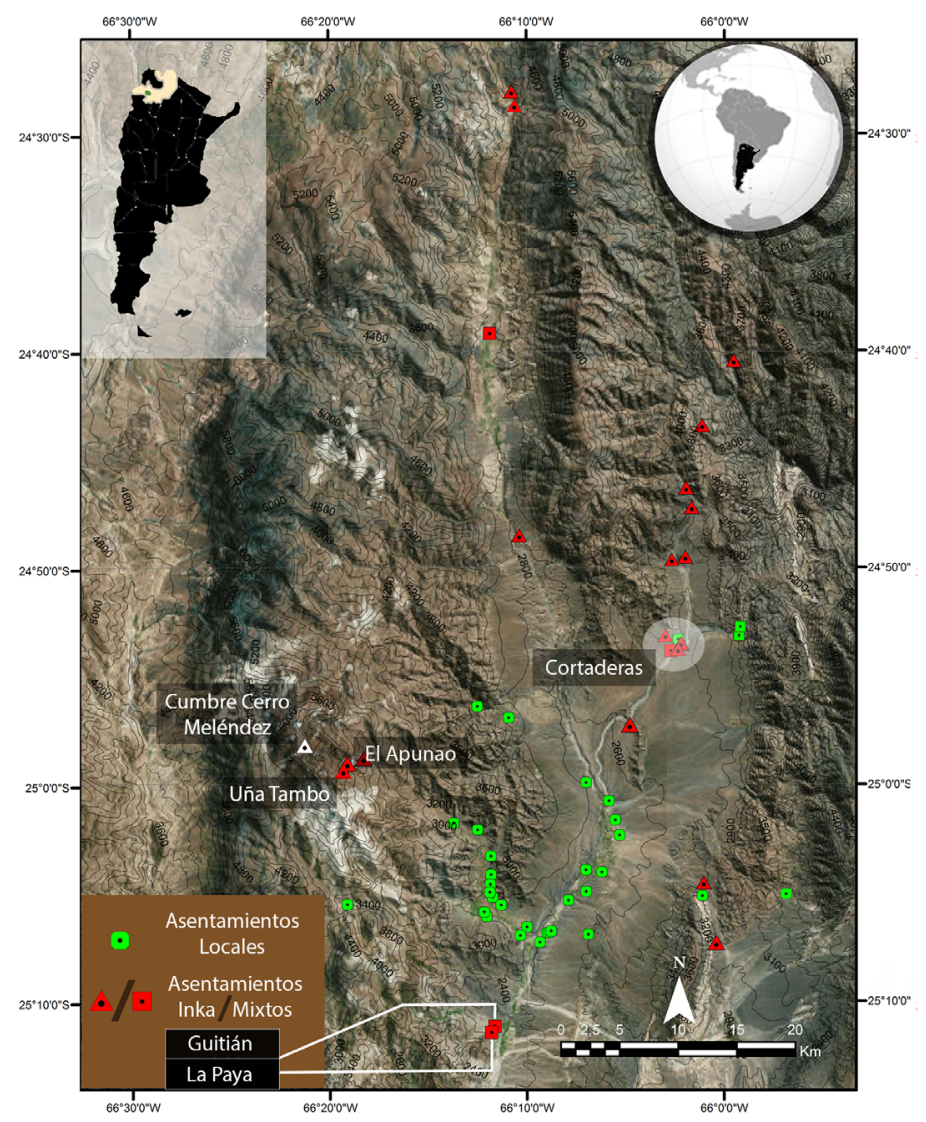

Figura 1. Porción septentrional del Valle Calchaquí Norte, principales áreas de ocupación e intervención inkaica y asentamientos que se tratan en este artículo. 
mente deshabitado. Tiempo atrás, uno de los autores propuso que la estrategia perseguida por los inkas al instalar sus centros más importantes en un sector periférico del paisaje social nativo apuntaba a crear un microcosmos inkaizado cuyo aislamiento le permitía evitar la interferencia local sobre las actividades promovidas por el Tawantinsuyu en la región (Acuto 1999).

En segundo lugar, los inkas parecen haber buscado establecer relaciones fluidas y ejercer una influencia más directa sobre la comunidad nor-calchaquí que habitaba el sitio conocido como La Paya (SSalCac 1). La construcción de una estructura de arquitectura inka de excelente manufactura y confeccionada casi exclusivamente en arenisca roja en el sector más elevado de este poblado local, la presencia de una importante cantidad de objetos de sello imperial en los entierros excavados, y la construcción de un pequeño asentamiento inka a tan sólo $345 \mathrm{~m}$ hacia el norte y noreste (Guitián SSalCac 2), atestiguan el vínculo especial que los habitantes de La Paya tenían con los representantes del Tawantinsuyu (Williams 2004).

El Tawantinsuyu también puso especial atención en una tercera área de gran relevancia simbólica en la región: los Nevados de Cachi. En el área de una de las cimas más elevadas de esta cadena montañosa (cerro Meléndez, $6020 \mathrm{msnm}$ ) los representantes imperiales construyeron, entre otras estructuras, una plataforma o rectángulo ceremonial de 12 × 6 m con sus lados más largos orientados en sentido este-oeste (Vitry 2008). Además, construyeron una serie de caminos y asentamientos especiales a distintos niveles altitudinales (especialmente entre los 4400 y los $5000 \mathrm{msnm}$ ) que incluyen albergues, complejos ceremoniales, estructuras y monolitos astronómicamente orientados y relacionados con la marcación de los equinoccios (Jacob et al. 2013; Moyano 2013: 202-208; 2014: 193).

¿A qué se debió el interés de los inkas por marcar su presencia en el área de los Nevados de Cachi? Para las comunidades andinas las montañas no eran meras geoformas sino entidades no humanas animadas (con agencia e intencionalidad) que interactuaban e influían activamente en la dinámica social de las comunidades humanas (Allen 2015; Dean 2015; Meddens 2015, entre muchos otros). Estas entidades brindaban protección pero a cambio debían ser cuidadas ya que, de ser desatendidas, podían causar daño a las personas o a sus tierras y animales. Algunos cerros, particularmente aquellos que se destacaban en el paisaje por su altura, forma y nieve permanente, eran considerados wak'a; sagrados en tanto que entidades ancestrales tutelares (apus, wamanis, awkillus, mallkus, entre otras variantes regionales) (Gil García 2012), o por ser pacarinas (lugares de origen de los ancestros fundadores). Al igual que con otros espacios sagrados localizados en los territorios provinciales, los inkas buscaron apropiarse del culto a los cerros diagramando y controlando las peregrinaciones hacia ellos. Para ello instalaron sitios, caminos y arquitectura ritual, comenzando ellos mismos a cuidar y honrar a estos lugares y entidades sagradas a través de pagos y ofrendas.

Una política común entre los inkas fue la transformación de las narrativas locales mediante la apropiación y actualización de las wak'as provinciales con el objetivo de que replicaran narrativas imperiales respecto de la ancestralidad inkaica en el territorio y el vínculo privilegiado entre los inkas y las entidades sobrenaturales (Acuto 2005; Van de Guchte 1999). Esta apropiación requirió del control sobre la accesibilidad física y visual a estos lugares sagrados, así como de la reglamentación de los sacrificios que se llevaban a cabo en su honor. Esta apropiación implicaba también un dominio exhaustivo del modo en que estas wak'as eran «presentadas». Es decir, 
las instancias de acuerdo a las cuales eran reveladas (Hyslop 1990; Niles 1992). La evidencia arqueológica detectada en el área de los Nevados de Cachi (Ceruti 2009; Jacob y Leibowicz 2011, 2014; Jacob et al. 2013; Moyano 2014; Vitry 2008) indica que el cerro Meléndez podría haber sido una importante wak'a y apu dentro del panteón nor-calchaquí.

Un aspecto común de los tres focos de ocupación inka en el valle Calchaquí Norte es el énfasis que el Tawantinsuyu puso en las actividades público-ceremoniales. Así lo atestigua la instalación de infraestructura ritual como ser plazas y plataformas ceremoniales (ushnus), y el modo en que buscaron escenificar el paisaje sagrado, el cual fue incorporado a la experiencia ritual y enmarcado a través de estructuras, mojones y el control de las vistas y los movimientos de las personas.

Este trabajo apunta a explorar los espacios públicos que los inkas construyeron en cada uno de aquellos tres sectores destacados del valle Calchaquí Norte a fin aproximarse a las experiencias rituales que allí tenían lugar y a los significados que los participantes de dichos rituales confrontaban al participar de los eventos públicos. Se busca ilustrar el modo en que los inkas manipularon estratégicamente la arquitectura de los espacios públicos a fin de orientar los cuerpos, influir sobre sus disposiciones y los sentidos, y construir narrativas materiales que los posicionaban como articuladores entre las poblaciones locales y las entidades sagradas y tutelares que habitaban el territorio.

\section{Espacios públicos y plataformas ceremoniales}

Sin lugar a dudas, uno de los escenarios más destacados de los asentamientos inkaicos, desde el Cuzco hasta los centros provinciales (tanto capitales regionales como centros administrativos más pequeños), es aquel conformado por las plazas ceremoniales y los edificios y estructuras asociados con ellas. Dentro de los poblados inka, los espacios públicos se destacan por su amplitud, centralidad y monumentalidad (Moore 1996). Pero quizá lo más interesante de estos espacios es la manera en que los inkas planificaron las performances rituales que allí se llevaban a cabo, las experiencias somáticas de los participantes (especialmente de la audiencia) y las narrativas materiales construidas y decodificadas a través de la performatividad corporal de las personas que allí concurrían. Entrar en las plazas, disponerse en su interior, escuchar y mirar, no eran aspectos librados al azar sino que constituían acciones intencionalmente planificadas en pos de comunicar e intentar la corporización de la naturaleza del nuevo orden colonial instaurado por el Tawantinsuyu. Implicaba en parte comunicar y actualizar las relaciones entre las personas y entre ellas y las entidades no humanas que poblaban el paisaje subterráneo, terrenal y celeste andino.

Una de las construcciones de mayor relevancia para las interacciones que se tejían dentro de las plazas inka era el ushnu. Tal como señala Hyslop (1990), este tipo de estructuras es quizá el más difícil de estandarizar y definir ya que es uno de los que más variabilidad presenta en cuanto a su composición general, los materiales empleados en su construcción, sus dimensiones, la geometría de la planta, las prácticas asociadas y su localización. De modo general, se trata de montículos con cimas planas o plataformas de piedra que suelen presentar escalinatas, canaletas y receptáculos para líquidos. También los hay conformados por simples rocas que se destacaban por su forma y que, en ocasiones, estaban talladas. 
Las fuentes históricas, así como la literatura antropológica y arqueológica, les han asignado a estas plataformas ceremoniales distintas funciones. Un entendimiento clásico de los ushnus que nos han legado varios cronistas es aquel que los caracteriza como un trono o asiento desde el cual el Inka o sus representantes provinciales conducían las ceremonias públicas y establecían y remarcaban la autoridad del Tawantinsuyu (Allen 2014: 72). Desde esta perspectiva, el ushnu constituía una herramienta administrativa mediante la cual el imperio organizaba sus territorios y a sus súbditos. Esto amerita considerar al ushnu como un concepto, a su vez complejo y variado, que operaba como un símbolo de la unión política del Cuzco con los centros provinciales y entre estos centros y las regiones bajo su jurisdicción (Hyslop 1990).

Adicionalmente, los ushnus se han vinculado a actividades de observación celeste y a mediciones astronómicas. Esta interpretación destaca la asociación ocasional de las plataformas con un pilar de roca destinado a la observación de los ciclos solares y a la regulación del calendario ritual y el calendario productivo ${ }^{5}$ (Staller 2008; Zuidema 1980).

Una de las interpretaciones más interesantes sobre los ushnus es aquella que remarca su naturaleza de axis mundi en el cual se intersectaban distintos planos existenciales y las fuerzas que operaban en cada uno de ellos (Zuidema 1980). El ushnu era un lugar de encuentros (tinku) y el Inka (o su representante) articulaba este encuentro entre esferas, fuerzas, entidades y elementos trayendo orden y equilibrio al mundo (Staller 2008: 293). La circulación de líquidos que se vertían como libaciones en el ushnu jugaba un rol central en la articulación entre aquellos planos, fuerzas y elementos. Por medio de estas libaciones se vinculaba y se establecía la comunicación entre la parte superior y celeste o Hanan Pacha, proveedora de agua de lluvia y lugar de residencia de las entidades celestes, el Kay Pacha o mundo terrenal de las comunidades humanas y las entidades no-humanas que habitan los territorios, y el Ukhu Pacha, mundo interno de la tierra, de las aguas subterráneas, y de los ancestros (entre otros elementos y entidades) (Meddens 1997; Meddens et al. 2008; Monteverde 2010; Pino 2004). En el Imperio Inka, los ritos agrícolas utilizaban el ushnu como medio material y simbólico a través del cual el agua era traída desde el mundo de arriba, se corporizaba en la parte media, y fecundaba la Madre Tierra (Pachamama). También se ha argumentado que al verter chicha dentro del ushnu se ofrendaba y alimentaba a las entidades sagradas del paisaje y a los ancestros difuntos. Varias fuentes históricas confirman esta relación entre ushnus y ofrendas y sacrificios (ver en Meddens et al. 2008: 349).

En pocas palabras, el ushnu funcionaba como un conducto a través del cual se vinculaba a las deidades del cosmos con las entidades sagradas del territorio, con la tierra, y con los ancestros del mundo de abajo, garantizando la circulación de las fuerzas vitales. En este esquema, el Inka o su representante era el mediador de este vínculo y de esta circulación. En pos de establecer estas conexiones, los ushnus fueron construidos en lugares que permitían ver y ser visto por las entidades sagradas que se buscaba honrar durante los rituales (Meddens et al. 2008: 341).

Una característica fundamental y recurrente de los ushnus era su capacidad de recibir y simbólicamente canalizar líquidos hacia los campos de cultivo, hacia los

\footnotetext{
5 De acuerdo a Staller, «Los ushnus integraban información astronómica y meteorológica, vinculándola con la subsistencia, el ritual y los ciclos religiosos así como también con las huacas de los alrededores» (2008: 289, traducción de los autores, cursiva en el original).
} 
lugares sagrados del paisaje y hacia los ancestros (Staller 2008; Zuidema 1980). En este sentido, Pino Matos (2004: 146) resalta la noción de ushnu como un lugar donde se ofrendaban líquidos o se efectuaban libaciones. En las plataformas, esto se materializaba en un sistema de drenaje subterráneo que conducía a un pozo o receptáculo de ofrenda. Por su parte, Farrington (2013) destaca ciertas propiedades arquitectónicas fundamentales del ushnu: un aditamento que dé la sensación de subir hacia el cielo (escaleras, banquetas o la plataforma en sí) y un elemento que brinde la impresión de descender y penetrar en la tierra como sería una cocha, un canal, una cueva, un pozo o una tumba. Relacionando también ushnus con líquidos y ofrendas, se ha señalado que estas estructuras constituían fuentes desde las cuales bebía el sol y desde las cuales los nobles inka bebían en honor al sol y a los ancestros (Meddens et al. 2008: 324; Staller 2008: 291). En palabras de Allen: «Sentado en su plataforma real al lado del pilar, atrapando los rayos de sol en un punto crítico de su trayectoria anual, vertiendo chicha por el drenaje y por su garganta, el Inca debe haberse convertido en una suerte de punto de conmutación cósmico de gran fuerza coercitiva» (Allen 2014: 72, traducción de los autores).

\section{Los inkas en la periferia del paisaje local: el caso del sitio Cortaderas}

El sitio Cortaderas (2453'32.72”S, 6602'09.89’O, $2750 \mathrm{msnm}$ ) (Figura 2) se emplaza en una zona del territorio nor-calchaquí apartada de los principales poblados locales. Allí, los inkas parecen haber buscado construir un paisaje propio alejado de las interferencias e influencias nativas. El sitio presenta cuatro sectores (con una superficie acumulada aproximada de $22 \mathrm{ha}$ ) que fueron descritos ampliamente en otra instancia (ver en Acuto 2004). Cortaderas Bajo (SSalCac 65) y Cortaderas Izquierda (SSalCac 43) son áreas de construcciones inkaicas entre las que se incluyen destacados complejos residenciales, públicos y administrativos. En la cima del cerro en cuya base se emplaza Cortaderas Bajo, se encuentra el sector denominado Cortaderas Alto (SSalCac 44). Se trata de un poblado conglomerado local cuyo posicionamiento en la cima, la existencia de un muro perimetral y las empinadas laderas que lo rodean sugieren una naturaleza defensiva (Williams 2004). Fue ocupado previamente a la llegada de los inkas a la región y abandonado una vez que éstos se instalaron allí (D`Altroy y Williams 1998). Finalmente, Cortaderas Derecha (SSalCac 65D), ubicado en la primera terraza sobre la margen occidental del río Potrero, es un pequeño poblado local construido en torno a un edificio inkaico central ${ }^{6}$.

Cortaderas Bajo, el sector que nos interesa en este trabajo, presenta dos complejos arquitectónicos en su lado oeste y una serie de construcciones más pequeñas de uso doméstico en su sección noreste (Acuto 2004). Hacia el centro de Cortaderas Bajo existe un espacio nivelado y libre de edificaciones de aproximadamente 800 $\mathrm{m}^{2}$. Esta posible plaza se encuentra delimitada en sus lados oeste, norte y noroeste por los muros perimetrales de los complejos arquitectónicos mencionados, mientras que sus lados norte y noreste están delimitados por un muro perimetral. El límite noroccidental de Cortaderas Bajo está definido por la ladera del cerro en cuya cima,

\footnotetext{
6 Se ha argumentado que este sector de Cortaderas fue edificado al momento de instalarse los Inkas en el área y que sus habitantes estuvieron dedicados a la producción y procesamiento de alimentos orientados a la economía política imperial (Acuto 2004).
} 


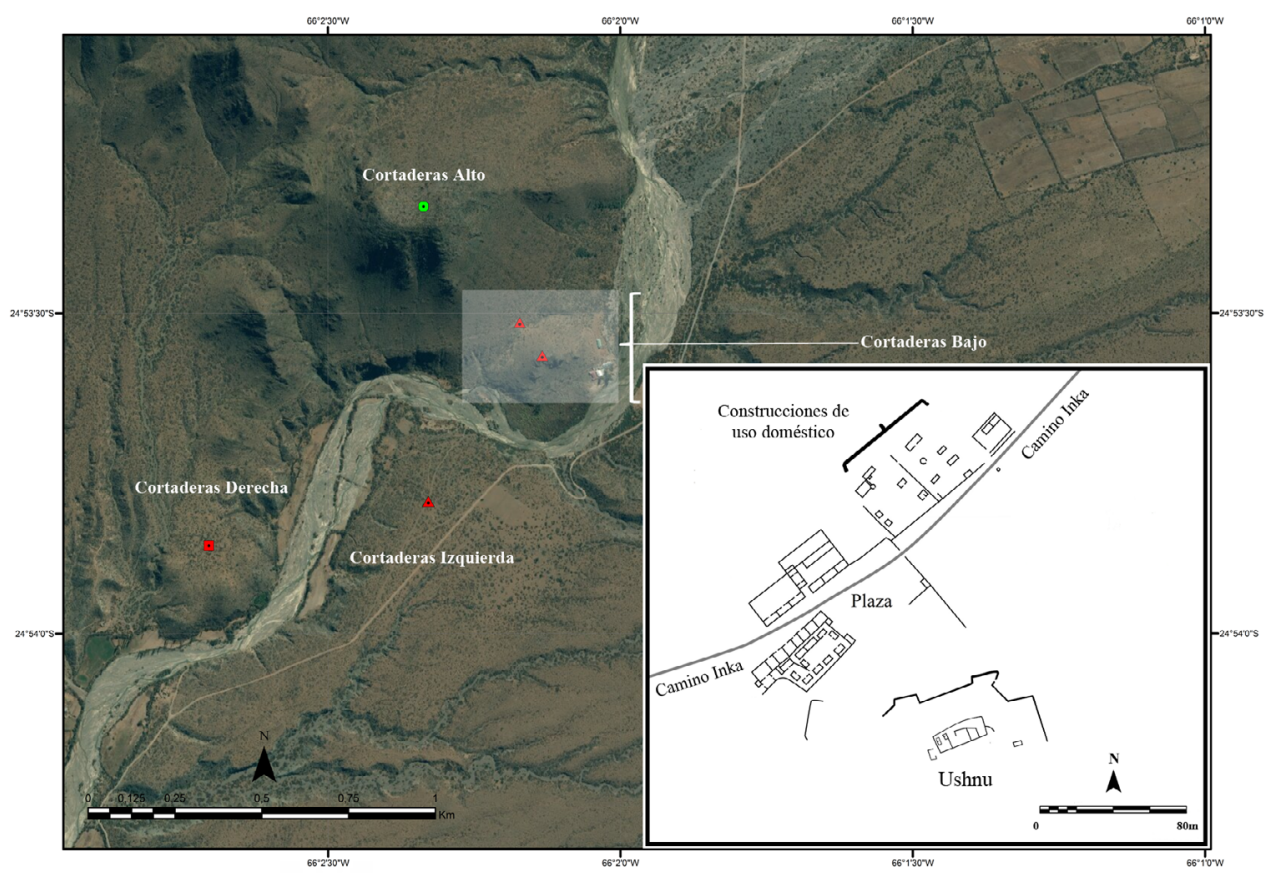

Figura 2. Complejo de Cortaderas y detalle de Cortaderas Bajo.

170 m más elevada respecto de la plaza, se encuentra el poblado-fortaleza o pukara local de Cortaderas Alto. El límite sur y suroriental está definido por un morro que se eleva $30 \mathrm{~m}$ de altura respecto de la plaza en cuya cima se emplazó una compleja plataforma de piedra con estructuras, muros divisorios internos, y una maciza muralla que la flanquea por sus lados norte y este (ver Figura 2).

Si bien esta plataforma fue interpretada como una fortaleza con la que los inkas habrían defendido sus asentamientos o al menos disuadido los ataques (D'Altroy et al. 2000; Hyslop 1984), se ha reevaluado esta interpretación sosteniendo que esta construcción fue un edificio ceremonial (Acuto et al. 2012). A partir de su emplazamiento, las características de sus fachadas, su articulación con la plaza (y la articulación de ésta con el camino inka que atraviesa el sitio en dirección suroeste a noreste), el despliegue de la muralla perimetral hacia el interior del asentamiento, y no hacia el valle de donde hipotéticamente podrían provenir los ataques, y el hecho de que se trata de una plataforma expuesta sin ningún tipo de parapeto de protección adicional, hace que se proponga que nos encontramos ante un ushnu antes que con una construcción de tipo defensivo o militar. Si bien no son comunes los ushnus ubicados al costado de las plazas, existen otros casos que se asemejan al de Cortaderas Bajo. A modo de ejemplo, podríamos señalar el ushnu ubicado sobre un pequeño morro localizado hacia el límite sudoeste de la plaza principal del sitio inka conocido como La Ciudacita o Nevados del Aconquija (Argentina) (Ataliva et al. 2010). Otro tanto puede decirse del sitio Tambokancha, en la región del Cuzco. Este sitio inka, estudiado por Farrington y Zapata (2003), presenta una plaza rectangular sin ushnu aparente en su interior. No obstante, los investigadores descubrieron que hacia el oeste, en la cima de una colina redondeada (denominada Colina del Ushnu), se emplazó una platafor- 
ma de piedra y una variedad de construcciones en las pendientes sur y este entre las que se destacaban escaleras, canales y baños y/o depósitos de agua. Notaron además que la arquitectura de la plaza estaba orientada en función de la cima de la colina que interpretaron como un ushnu.

El núcleo del ushnu de Cortaderas es una plataforma subrectangular de $301 \mathrm{~m}^{2}$. Su cara suroriental, que se orienta hacia el valle y es la mejor conservada, presenta actualmente 3,47 m de altura y está confeccionada con rocas de campo seleccionadas y en algunos casos evidentemente canteadas y asentadas con abundante mortero, a razón de 49 rocas por $\mathrm{m}^{2}$ con una separación media de $0,04 \mathrm{~m}$. La fachada que se orienta hacia la plaza, exhibe actualmente $2,3 \mathrm{~m}$ de altura y está confeccionada con rocas seleccionadas y asentadas con abundante mortero, a razón de 50 rocas por $\mathrm{m}^{2} \mathrm{y}$ una separación media de $0,04 \mathrm{~m}$. El interior de esta plataforma presenta cuatro estructuras rectangulares pequeñas en su área occidental y muros divisorios en su lado oriental.

No se han observado escalinatas u otro rasgo que indique algún acceso pautado. Sin embargo, debe tenerse en cuenta la existencia de un viacrucis moderno que trepa el morro desde el sur hasta la cumbre del morro en el que se emplazó la plataforma. Es usual que los caminos y senderos que las comunidades de la región construyen, reconstruyen o emplean en la actualidad se superpongan con caminos antiguos. No es de extrañar que esa haya sido la manera de acceder al ushnu y que aquellos que conducían las ceremonias desde el ushnu accedieran a él sin ser vistos por la audiencia reunida en la plaza. Esto mismo se ha visto en otros sitios en los cuales los oficiantes se mantenían fuera de la vista de los invitados en ciertos momentos de las ceremonias, tal como en el caso de Maukallaqta en la región de Paruro cerca del Cuzco (Bauer 1992). Mientras que la falda sur del morro probablemente hubiese servido para acceder a la plataforma, su falda septentrional presenta un muro de 142,2 $\mathrm{m}$ de longitud que actualmente conserva una altura de 1,97 m, un espesor de $0,7 \mathrm{~m}$ de ancho, y un posible acceso de 1,2 $\mathrm{m}$ de ancho en una sección del muro en el noreste. Las técnicas constructivas de este muro no exhiben el cuidado que fue dado a la plataforma, siendo las rocas de tamaño variable, con una separación media de $0,06 \mathrm{~m}$ y a razón de 47 rocas por $\mathrm{m}^{2}$.

¿A qué narrativas materiales se exponían aquellos que se acercaban a Cortaderas para participar de actividades ceremoniales auspiciadas por los inkas? Al respecto, se debe tener en cuenta que el foco de ocupación local se concentraba hacia el suroeste. Así que es posible asumir que los visitantes locales que participaban de eventos públicos en Cortaderas Bajo (inclusive aquellos que habitaron Cortaderas Derecha) ingresaban a la plaza por su entrada posicionada en el noroeste, por un tramo de camino que atraviesa Cortaderas Bajo y recorre enteramente el lado norte de la plaza (Hyslop 1984).

Aquellos que se aproximaban a fin de participar de eventos ceremoniales en la plaza debían primero transitar un pasillo definido por dos complejos arquitectónicos. Al girar la vista hacia la derecha, los visitantes podían tener acceso visual al interior de, al menos, cinco de los ocho recintos en hilera que se encuentran a la vera del camino. Se ha sugerido, dada su forma, disposición y tamaño, que es posible que estos recintos hayan sido almacenes (Acuto 2004). Si esta hipótesis se ve corroborada, los inkas pudieron haber ofrecido a los visitantes locales un panorama de los recursos y riquezas que acumulaban y tenían para entregar en el ciclo redistributivo andino. Exactamente lo opuesto sucedía con el complejo arquitectónico que los visitantes encontraban a su izquierda, en el que la disposición no alineada de sus accesos im- 

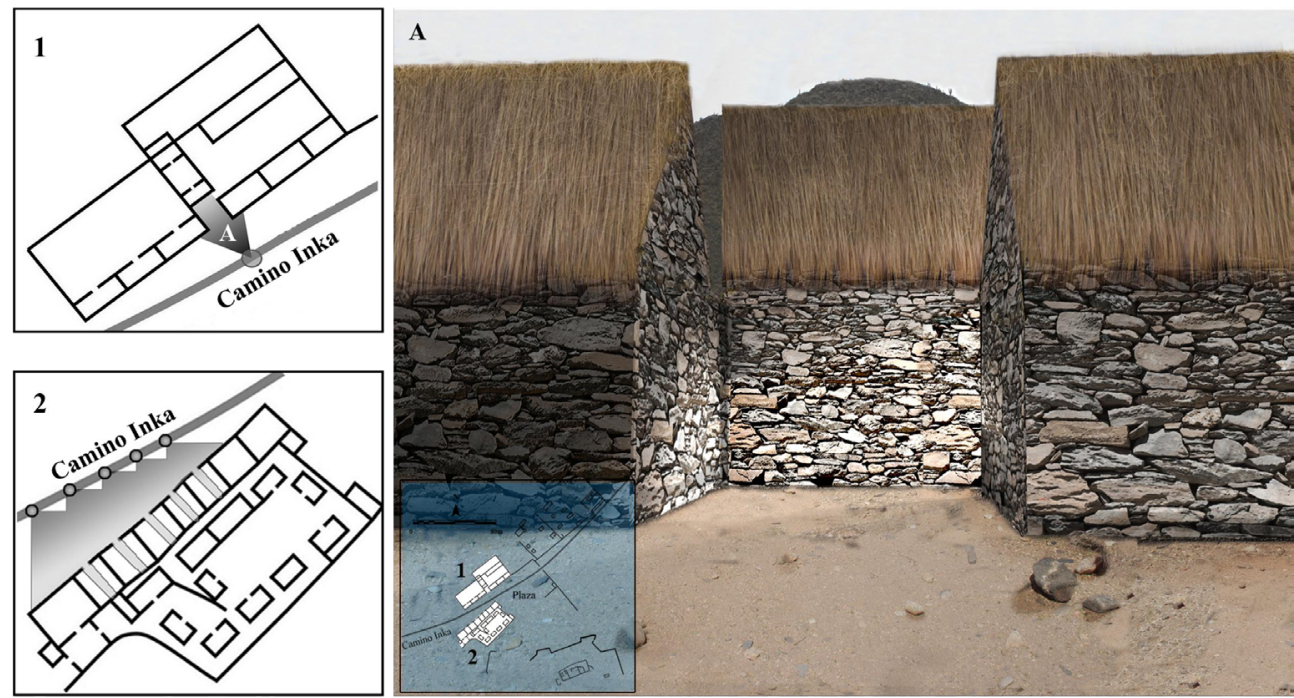

Figura 3. Accesibilidad visual en el interior de los complejos arquitectónicos lindantes al camino de ingreso a la plaza de Cortaderas.

pedía a las personas proyectar la vista hacia el interior del complejo (Figura 3). Es decir que los inkas parecen haberse ocupado explícitamente de ocultar el interior de este último complejo. Algo similar ocurre con el área residencial inka hacia el noreste, donde el nivel topográficamente inferior del camino y la presencia de altos muros impedían proyectar la vista hacia el interior, haciendo imposible que quienes circulasen por allí accedieran a la cotidianeidad de la vida imperial.

El ingreso a la plaza por su entrada noroeste introducía a los visitantes a un espacio abierto cuya superficie estaba orientada hacia el morro en donde se emplazó el ushnu. Los participantes debieron posicionarse en el interior de la plaza dirigiendo sus miradas hacia el ushnu y encontrándose a la vez con un sólido muro perimetral que inhibía el acceso no pautado a la plataforma. Por su parte, los especialistas rituales del Tawantinsuyu debieron haberse preparado fuera de la vista de los visitantes y ascendido hasta la plataforma por su lado sur. Durante los trabajos de campo se pudo determinar que la acústica del entorno permitía que los mensajes y sonidos que se emitiesen desde la plataforma llegasen con claridad a las personas agrupadas en la plaza de abajo. No obstante, aún no se han realizado análisis complementarios de dispersión sonora tales como lo que se han llevado adelante en Guitián (ver en Ferrari et al. 2017).

Mientras que el ambiente construido de la plaza motivaba que aquellos allí reunidos orientasen su vista hacia el ushnu, aquellos ubicados sobre la plataforma no sólo podían observar a quienes estaban en la plaza sino mirar, conectarse, hacer referencia y convocar simbólicamente a otros lugares y elementos de los alrededores como ser rasgos topográficos de gran relevancia simbólica. Tal es el caso de Los Cerrillos, un destacado lugar de culto local (Acuto, Gilardenghi y Smith 2011), y la ya mencionada cadena montañosa de los Nevados de Cachi entre cuyas cumbres se encuentra el mencionado cerro Meléndez (Figura 4).

Tanto durante la aproximación a Cortaderas Bajo como una vez dentro de su espacio público, las personas confrontaban una imagen contrastante. El contrapunto 

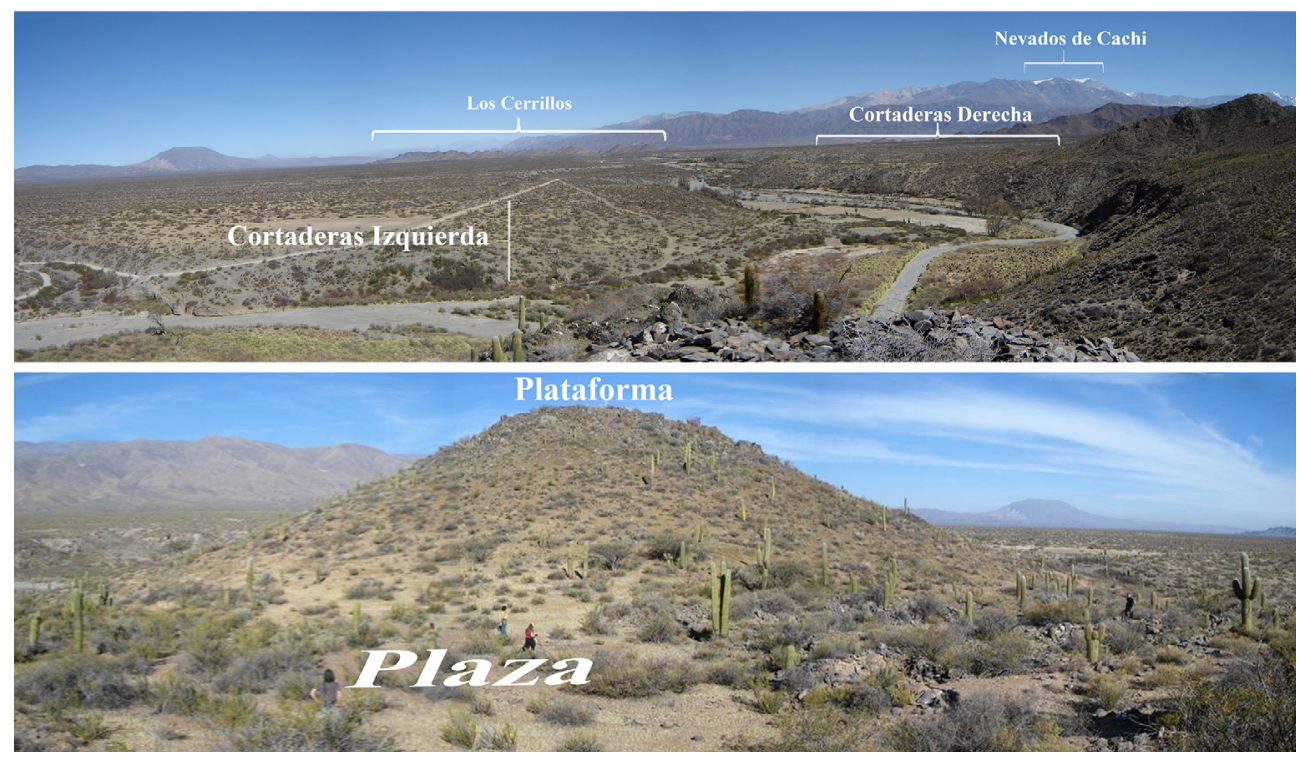

Figura 4. Arriba: Visibilidad de asentamientos y rasgos topográficos de relevancia desde el ushnu de Cortaderas hacia Suroeste del valle. Abajo: Vista de la plaza y el morro en cuya cima se emplazó la plataforma.

entre el flamante ushnu inka y la desierta fortaleza-poblado local contenía una poderosa narrativa colonialista y una clara representación de un orden previo suprimido y removido por el poder del Tawantinsuyu. Esto debió haber constituido un espectáculo impactante para los nor-calchaquíes, quienes enfrentaban simultáneamente un símbolo de conquista y representación de un nuevo orden. La posición del ushnu disponía los cuerpos de modo que las personas se encontrasen rodeadas de edificaciones inkaicas y la atención se concentrase en la flamante plataforma excluyendo de la escena al pasado local.

En definitiva, la configuración del ingreso a Cortaderas Bajo hace pensar en una escenificación general enteramente coordinada por el Tawantinsuyu. En ella, se explotaba al ushnu como elemento protagonista y se controlaba la participación local en la materialidad imperial. Llegar a Cortaderas Bajo implicaba participar de una narrativa de conquista que presentaba los dos agentes principales en el mismo plano de actuación ya que el emplazamiento del viejo poblado y la flamante plataforma se veían desde el camino que llevaba a la plaza con mucha anterioridad. Adentrarse en la plaza reposicionaba a los agentes locales ya no en relación a su pasado sino a su nuevo presente. En este esquema, la posibilidad de invocar y comunicarse con las entidades no humanas fundamentales del paisaje nor-calchaquí durante las ceremonias quedaba reservada a los representantes imperiales.

\section{Los inkas en la cotidianeidad local: el caso de La Paya/Guitián}

Como parte de su estrategia de colonización del valle Calchaquí Norte, los inkas instalaron un pequeño asentamiento de aproximadamente 1,6 ha denominado Gui- 

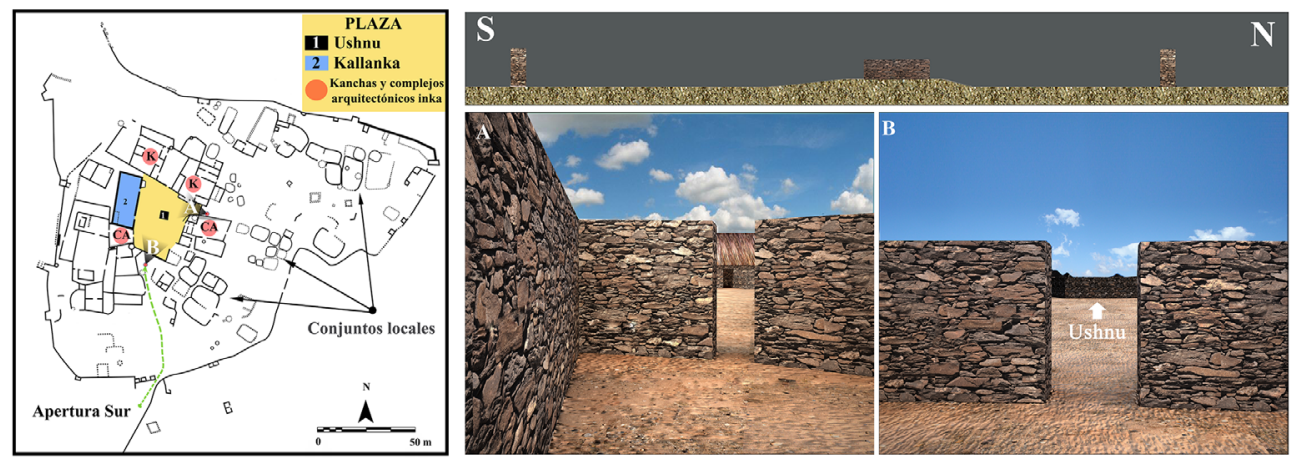

Figura 5. Plano bidimensional de Guitián y accesibilidad visual de la plaza y el ushnu de Guitián para los residentes en los conjuntos locales (A) y para quienes ingresaran a través del acceso sur (B). Arriba a la derecha, corte que expone el desnivel del ushnu respecto del nivel de ocupación de la plaza.

tián (SSalCac 2, $25^{\circ} 11^{\prime} 06.05$ 'S, 66¹1'30.17'O. $2288 \mathrm{msnm}$ ) a tan sólo $345 \mathrm{~m}$ de uno de los más importantes poblados de la región: La Paya (SSalCac 1). La relación que mantuvieron los representantes del Tawantinsuyu con la comunidad de La Paya implicó una transformación en su estructura social y, como resultado de este proceso de contacto cultural y colonización, comenzó a mostrar evidentes signos de estratificación y distinción (Acuto 2010, 2011; Kergaravat y Amuedo 2012).

Este proceso de fragmentación y distinción encontró un correlato espacial evidente en la reorganización de un sector del asentamiento mediante la construcción de estructuras inka en su interior (entre ellas la conocida como Casa Morada, Ambrosetti 1907) y mediante la reorganización de la accesibilidad externa y la circulación interna de dicho sector (Ferrari 2016; González y Díaz 1992). Adicionalmente, parte de este proceso implicó que algunos residentes de este poblado obtuvieran objetos de estilo inkaico (Acuto, Kergaravat y Amuedo 2011).

La influencia inka sobre la comunidad de La Paya no se limitó a transformar el mundo de la vida cotidiana local, sino que provocó un serio impacto sobre su vida ritual. Mediante la instalación de Guitián, los inkas parecen haber buscado cooptar, centralizar y redefinir las actividades público-ceremoniales, invistiéndolas de nuevas relaciones y sentidos (Acuto et al. 2012; Ferrari 2012). Ahora bien, ¿qué tipo de experiencias se articulaban durante las actividades público-ceremoniales que ocurrían en Guitián y qué narrativas coloniales se comunicaban durante su desarrollo?

Basta observar el plano de Guitián (Figura 5) para entender la centralidad y gravitación que la plaza tuvo en este asentamiento. Prácticamente todos los sectores orbitan en torno al espacio público. La plaza de Guitián $\left(935 \mathrm{~m}^{2}\right)$ cuenta con un pequeño ushnu ubicado hacia su centro, ligeramente desplazado hacia el norte. Actualmente, sus muros dobles conservan un ancho promedio de $0,56 \mathrm{~m}$ y una altura media de 0,93 $\mathrm{m}$. Se trata de muros de ángulos internos y externos rectos construidos con rodados fluviales y rocas tabulares dispuestas de modo horizontal sin modificación alguna a razón de 28 por metro $^{2}$, con una separación media de $0,04 \mathrm{~m}$, y asentadas con abundante mortero del lado interno. Las excavaciones que se realizaron en el interior del ushnu y contra su fachada sur, junto con las últimas mediciones realizadas, permiten asignar a la plataforma una superficie mínima de $16 \mathrm{~m}^{2}$. 
Directamente asociadas a la plaza se emplazaron los complejos arquitectónicos inkaicos. Entre ellos, dos kanchas ${ }^{7}$ ubicadas sobre el lado norte de la plaza y un clásico edificio inkaico denominado kallanka sobre el lado oeste de la plaza. Dos complejos arquitectónicos adicionales la delimitan en sus lados este y sudoeste. Todos estos complejos presentan accesos directos a la plaza. En la periferia oriental y septentrional del asentamiento se encuentran las construcciones locales ${ }^{8}$, sin accesos directos a la plaza.

La arquitectura misma y el diseño espacial de Guitián conforman una clara metáfora de la demarcación entre representantes imperiales y locales; entre quienes ocupaban el centro y tenían acceso directo y control sobre el espacio público, y aquellos que se localizaban en la periferia. Resulta claro que los representantes del Tawantinsuyu ingresaban a la plaza a través de seis accesos directamente vinculados a sus recintos. Otros tres accesos, posiblemente destinados a la participación local, conectaban la plaza con aperturas en la muralla perimetral del asentamiento a través de claros senderos.

La altura de los muros de la plaza, en conjunto con la posición y el ancho del pequeño acceso de $0,6 \mathrm{~m}$ que la vinculaba con la periferia local, limitaban la intervisibilidad entre la plaza y esta periferia ocultando el ushnu para los conjuntos locales (Figura 5). Esta barrera física y visual restringía fuertemente la participación de los residentes locales, excluyéndolos parcialmente tanto de la cotidianeidad imperial como de las ceremonias llevadas adelante en la plaza. A modo de hipótesis se propone que esta entrada, ubicada en el noreste a la plaza, pudo haber sido simplemente un acceso ocasional para aquellos agentes locales que colaboraran de modo efímero con las actividades públicas llevadas a cabo por los representantes del Tawantinsuyu. En este esquema general en el que el acceso noreste podría haber tenido una función predominantemente utilitaria, el acceso sur se revela como un elemento central en la inserción de los grupos locales a la coreografía imperial.

Al ser convocados a algún evento público auspiciado por el Tawantinsuyu, los visitantes (posiblemente residentes del poblado vecino de La Paya, hacia el sur) podrían haber ingresado a Guitián a través de una estrecha apertura localizada en el sur de su muro perimetral. Luego debieron haber caminado hacia la plaza para ingresar por una entrada de 1,1 $\mathrm{m}$ de ancho localizada en la sección media de su muro sur. Ahora bien, ¿qué panorama encontraban los visitantes de La Paya al ingresar al espacio público-ceremonial de Guitián?

Las excavaciones que se realizaron en las secciones sur, media y norte de la plaza nos permitieron estimar la altura mínima de sus muros en $2 \mathrm{~m}$. Sin embargo, el aspecto más interesante fue descubrir que la superficie de la plaza no estaba enteramente al mismo nivel. Esto es, el área donde se emplazaba el ushnu se encontraba sobreelevada 0,63 m, llevando la superficie superior del ushnu a un mínimo de 1,5 m sobre el piso original de la plaza. Esto daba al ushnu una preeminencia escenográfica que lo con-

\footnotetext{
Unidad de arquitectura inkaica compuesta por un gran recinto de superficie variable con tres o más estructuras (a su vez, de superficie y perímetro variable) sin subdivisiones internas y emplazadas en su perímetro interno liberando un espacio sin estructuras en el centro (Hyslop 1990). Se han señalado funciones diversas de estos complejos de estructuras: unidades residenciales, templos, palacios, y locaciones de manufactura especializada (Acuto y Gifford 2007; Hyslop 1990).

8 Su diseño de planta, las técnicas constructivas aplicadas, la articulación entre recintos, y su disposición general en conjuntos discretos de estructuras (características que encuentran reflejo en el sitio predominantemente local de La Paya), indican que se trataría de complejos locales (Ferrari 2012).
} 

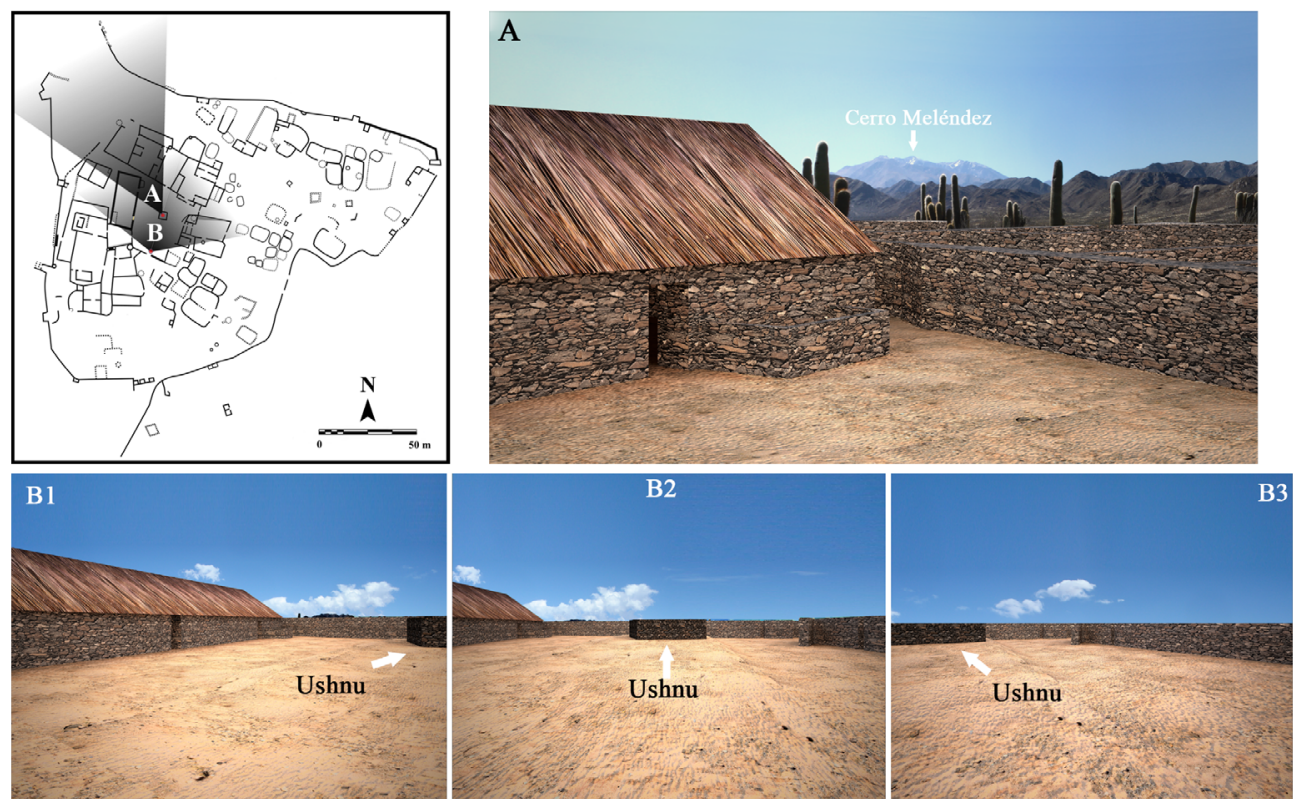

Figura 6. Visibilidad del cerro Meléndez para los oficiantes rituales (A) y visibilidad propuesta para los ingresantes a través del acceso Sur (B1 a 3).

vertía en el protagonista del espacio público. Al ingresar al interior de la plaza a través del acceso sur, los visitantes de La Paya se encontraban en el lado más bajo de una superficie desnivelada y con una vista directa del ushnu. Incluso antes de adentrarse a la plaza obtenían una vista del ushnu elevado enmarcado por el acceso (ver Figura 5).

Una vez dentro de la plaza, la experiencia era la de un espacio recluido y rodeado por un ambiente construido completamente inkaizado. Lo circunscripto del espacio público de Guitián y la altura de los edificios que lo rodeaban de manera compacta restringían la vista hacia el exterior de la plaza. Esto no se aplicaba a el/los oficiantes rituales quienes, toda vez que posicionados sobre el ushnu, podían observar e invocar al cerro Meléndez (Figura 6).

Al igual que en Cortaderas, la intención de los inkas fue impedir que la vista de los participantes de las actividades públicas penetrara mucho más allá de la fachada de los edificios inkaicos. A través de la construcción de vestíbulos y accesos contiguos pero no alineados, los representantes del Tawantinsuyu buscaron evitar el acceso visual a la cotidianeidad de la vida imperial (Acuto et al. 2012). A su vez, nuevamente al igual que en Cortaderas, los representantes imperiales se ocuparon de reservar el contacto visual con la cumbre del cerro Meléndez a quienes estuviesen sobre la plataforma y no a los participantes en el lado sur de la plaza, cuya atención se orientaba principalmente a lo que sucedía en este microcosmos ceremonial inkaico.

Las excavaciones dentro del ushnu revelaron la existencia de una pequeña estructura semielipsoidal adosada al lado interno del muro norte del ushnu a modo de receptáculo, de $0,7 \times 0,4 \mathrm{~m}$ de lado y una profundidad media de $0,43 \mathrm{~m}$. Creemos que esta pequeña estructura, en línea con lo que se ha documentado en otros ushnus, pudo haber sido utilizada para depositar ofrendas y/o verter libaciones. 
La restricción a la posibilidad de los locales de proyectar la vista hacia ciertos elementos del paisaje circundante probablemente se haya revertido al momento de evacuar la plaza. Si bien es algo que necesita corroboración, creemos que es posible que, una vez concluidas las actividades ceremoniales dentro de la plaza, los invitados la abandonaran a través de una abertura de 1,7 $\mathrm{m}$ de ancho localizada en la esquina noroeste. Esto implicaba transitar un estrecho pasillo definido por el exterior de la kallanka y el exterior de la kancha ubicada al noroeste de la plaza. Este pasillo empalmaba a su vez con un sendero que conducía a una de las entradas del sitio situada en el noroeste del muro perimetral. En este esquema, los visitantes locales habrían entablado contacto con la cumbre del cerro Meléndez en una única instancia: una vez que abandonaban la plaza, atravesaban el mencionado pasillo y giraban hacia el norte para dirigirse hacia la apertura perimetral. La integración controlada de esta destacada cumbre a la escenografía ceremonial que tenía lugar en Guitián muestra un interés explícito por hacer de esta montaña un elemento importante dentro de la coreografía ritual general.

En definitiva, estar en la plaza de Guitián sujetaba a sus visitantes a un lugar completamente nutrido de materialidad imperial, con énfasis en la plataforma ceremonial y en donde la posibilidad de proyectarse hacia la cumbre del cerro Meléndez estaba evidentemente regulada y secuenciada. Los muros de los edificios, particularmente en el caso de la kallanka, clausuraban la vista hacia cualquier otro rasgo topográfico de las inmediaciones (efecto más evidente aún si se integrasen más techumbres al modelo). En definitiva, si bien el cerro Meléndez seguramente era invocado en esta coreografía, durante la estadía en el espacio público este contacto estaba reservado para quien/es estuviesen arriba del ushnu.

\section{Construyendo y habitando en el territorio del cerro: los sitios El Apunao y Uña Tambo}

El área de los Nevados de Cachi también captó la atención de los inkas, quienes marcaron su presencia en la zona a través de la instalación de sitios, caminos, y el auspicio de actividades que involucraron peregrinajes y rituales. Tres lugares se destacan en esta área: la mencionada plataforma en la cima del cerro Meléndez (ver en Vitry 2008), y los sitios El Apunao y Uña Tambo. El Apunao (SSalCac 174, 24 59 '40.1' 'S, 66 19 '04.9'W) se encuentra emplazado en un pequeño circo glaciar ubicado en una quebrada inferior entre los cerros Meléndez y Pilar de las Pailas a una altura de 4753 msnm (Jacob y Leibowicz 2011, 2014). El sitio presenta dos sectores ubicados a 100 $\mathrm{m}$ de distancia y separados por un curso de agua (Figura 7). Uno de estos sectores, ampliamente descrito en otros trabajos (ver en Jacob y Leibowicz 2011, 2014, Jacob et al. 2013), cuenta con seis estructuras; cuatro de ellas de cuidada manufactura para darle a los muros ángulos interiores y exteriores rectos, vanos de ingreso rectangulares y claros escalones en ciertos casos. Es probable que estos recintos hayan servido de albergue para quienes concurrían al asentamiento. Las dos estructuras restantes, de trazado subcircular y mampostería irregular, se asemejan a ciertos recintos presentes en Uña Tambo. Allí es común observar el aprovechamiento de grandes bloques a los que se adosaron muros para delimitar estructuras.

El otro sector (Figura 8), que es el que interesa tratar en este artículo, tiene como rasgo más saliente una plataforma tipo ushnu rellena y aplanada, de $9 \mathrm{~m} \mathrm{x} 7 \mathrm{~m}$ máxi- 


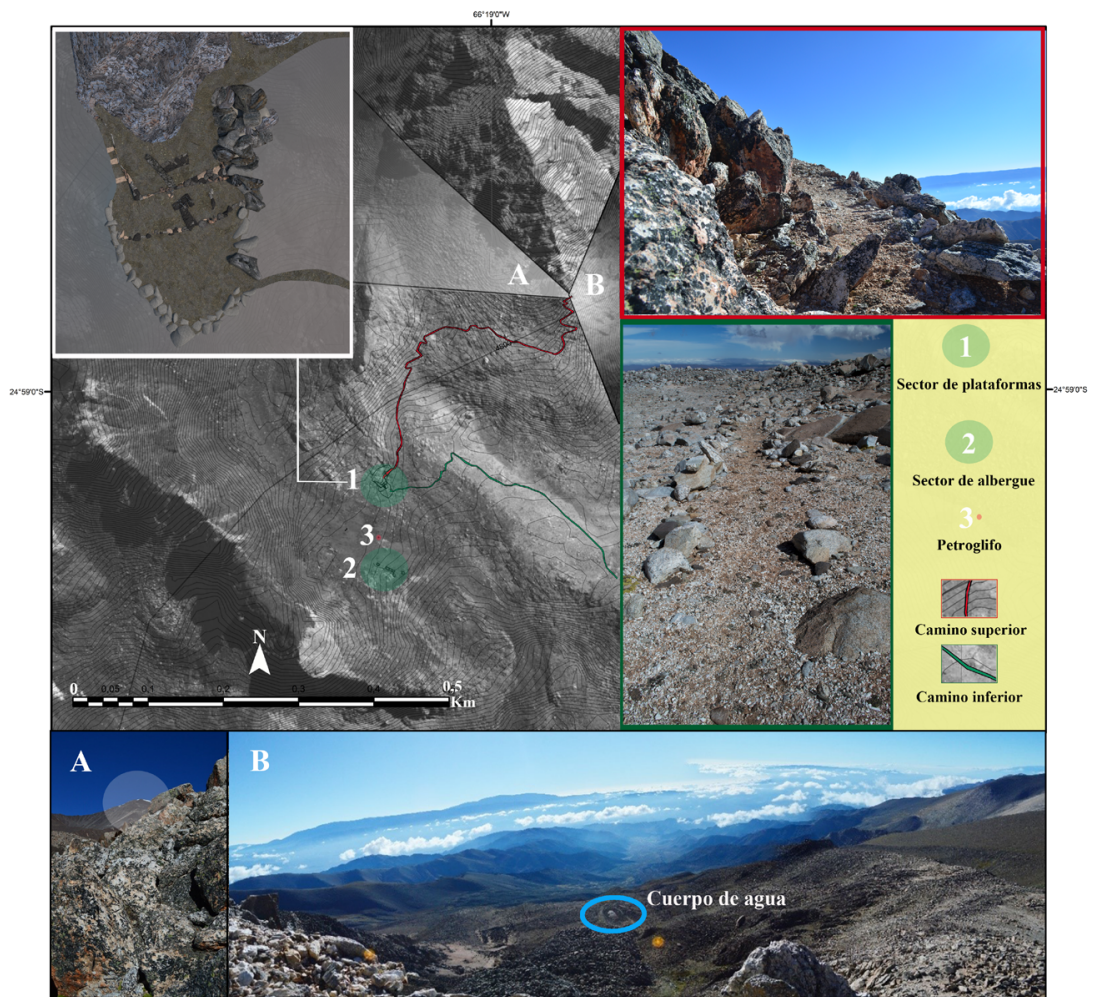

Figura 7. Complejo de El Apunao, tramos de camino imperial que desembocan en el sector de plataformas y vistas desde el tramo más elevado de camino.

mos de lado y hasta 1,4 m de alto, adosada a un llamativo promontorio rocoso de color blanquecino (se denominará plataforma inferior de aquí en adelante). Sobre ella se construyó una segunda plataforma cuidadosamente enlajada de $0,4 \mathrm{~m}$ de altura y $3,8 \mathrm{~m}^{2}$ de superficie. Hacia el lado sur de la plataforma inferior se levantó un muro doble elevado tan sólo $0,2 \mathrm{~m}$ de la superficie actual que corre hacia el sudeste a lo largo de $4,7 \mathrm{~m}$. Su recorrido no parece ser casual ya que desciende en dirección a los campos de cultivo de los valles inferiores.

Al pie de la plataforma inferior, a una distancia $1 \mathrm{~m}$, se encuentra una estructura rectangular de $1,05 \mathrm{~m}$ x 0,88 $\mathrm{m}$. Ésta fue excavada en el suelo, su base fue enlajada, y presenta dos aperturas: una en su lado sudoeste y otra en su lado sudeste. Al despejar el sedimento aledaño a esta pequeña estructura rectangular se halló un piso enlajado de $0,87 \mathrm{~m}^{2}$ adjunto a su lado sudoeste. Se considera que la estructura excavada y enlajada podría haber funcionado como un receptáculo para libaciones, mientras que el pequeño espacio enlajado adyacente pudo haber sido el lugar donde se situaba alguno de los oficiantes del ritual.

Tanto el área de plataformas como el área del receptáculo enfrentan un espacio abierto, llano y toscamente delimitado de aproximadamente $140 \mathrm{~m}^{2}$. Esta zona pudo haber funcionado como un pequeño espacio público ya que en él desemboca el camino inka que proviene de los valles inferiores. Adicionalmente, no posee conexión 


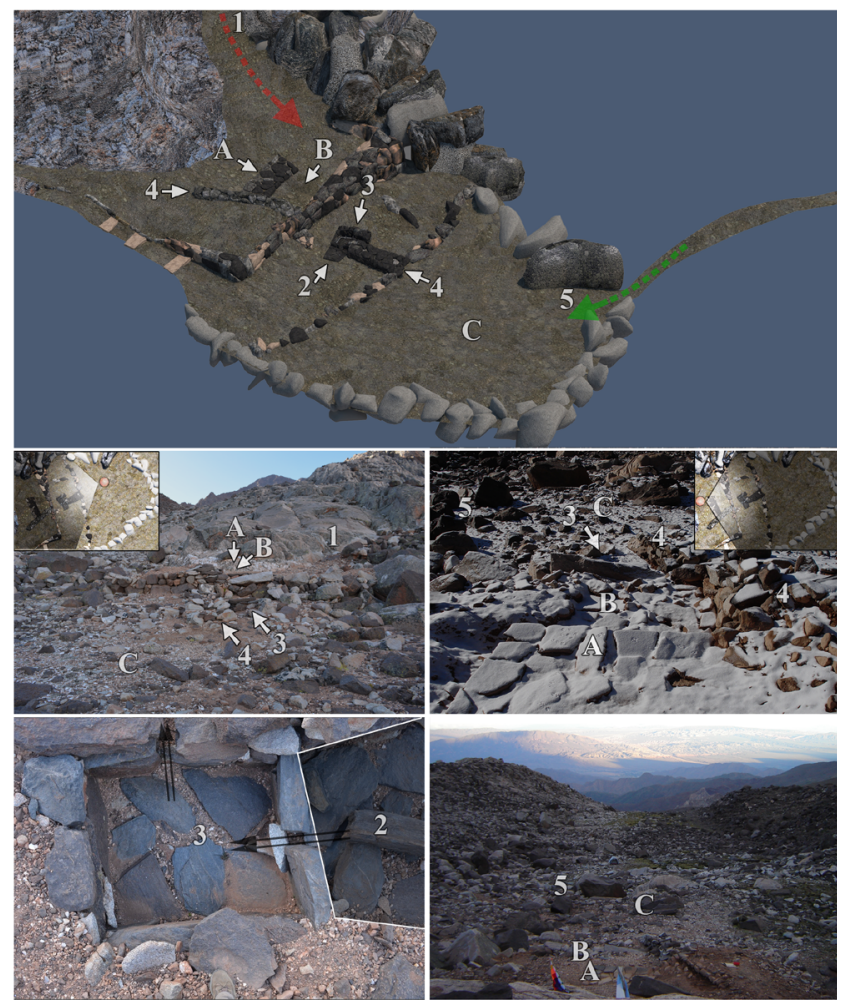

Figura 8. Arriba: Complejo de plataformas de El Apunao y rasgos mencionados en el texto. Ingreso de los oficiantes (1), plataforma superior enlajada (A), plataforma inferior (B), piso enlajado (2) contiguo al receptáculo para libaciones (3), muros/canaletas de drenaje (4), espacio de reunión (C) e ingreso de los visitantes (5). Centro izquierda: vista de las plataformas de frente. Centro derecha: vista hacia los valles inferiores. Abajo izquierda: detalle del receptáculo para libaciones. Abajo derecha: vista general de la plataforma hacia los valles inferiores.

directa con las plataformas y con el área con el receptáculo ya descripto. Tanto las plataformas como el muro y el canal de drenaje se encuentran direccionados hacia la quebrada de Las Arcas y hacia donde se halla el amplio sitio local de Las Pailas (SSalCac 18) y sus extensos campos de cultivo. Adicionalmente, sobre el curso de agua que divide los dos sectores del El Apunao detectamos un petroglifo con 187 círculos grabados (Jacob et al. 2011), motivo inédito para la región (Lanza 1996, 2000). Es de destacar que 187 son la cantidad de días que separan los equinoccios de otoño y de primavera y que recientes estudios arqueoastronómicos han demostrado la orientación de la plataforma respecto de la salida y puesta de la luna en su posición de extremo norte y en relación con los equinoccios (ver Moyano 2014: 193).

La presencia de una plataforma ushnu, un receptáculo para libaciones con drenaje, muros que emulan canales direccionados hacia los valles inferiores, su asociación con un llamativo promontorio blanquecino y con el curso de agua que desciende de las alturas de los cerros para nutrir al río Las Arcas y regar una de las principales áreas agrícolas prehispánicas de la región, la orientación astronómica de la de la plataforma y su especial vínculo con los equinoccios, y la presencia de un petroglifo posiblemente vinculado con el calendario lunar, demuestran la relevancia simbólica de El Apunao. El sitio tuvo una profunda relación con dos de las más importantes fechas del calendario agrícola como fueron la temporada de siembra y la época de cosecha (Moyano 2014). Esta evidencia sugiere fuertemente que El Apunao constituyó un lugar de peregrinaje relacionado con el culto y pago al río y con el control simbólico del agua. 
Ahora bien, ¿cómo estaba diagramada la participación de los oficiantes de y los asistentes a las actividades rituales? ¿Qué movilidades y vistas eran promovidas por el emplazamiento?

Al sector de plataformas llegan claramente demarcados dos tramos de camino (ver Figura 7). Por uno de ellos arribaban al pequeño espacio público los invitados a los eventos rituales. Por el otro, llegaban a las plataformas quienes patrocinaban y protagonizaban estos eventos. Invitados por los representantes imperiales, los peregrinos locales recorrían el camino imperial para llegar al sitio (al menos 2,1 km de este trayecto están claramente delimitados y reforzados con muros de protección), pero justo antes de llegar a él debían transitar una extensa explanada de aproximadamente $200 \mathrm{~m}$ flanqueada por una zona de derrubio al Sur y e inclinadas laderas al Norte. Esto no es un aspecto menor, ya que la mencionada zona de derrubio restringe la posibilidad de ver el sector de plataformas. Tanto la plaza como el complejo de plataformas se revelaban a los invitados una vez que cruzaban la zona de derrubio, trascendían la cota de los 4750 msnm y descendían por el camino hasta desembocar directamente en el pequeño espacio público. En este esquema, las plataformas y el blanquecino promontorio de trasfondo se revelaban como el foco de atención principal de los visitantes (ver Figura 8).

Un segundo camino, posiblemente reservado a los representantes del Tawantinsuyu, tenía su origen tras un promontorio cercano y finalizaba en la plataforma (ver Figura 7). Ubicados a $4839 \mathrm{msnm}$ detrás de un afloramiento que los mantenía ocultos, los oficiantes de los rituales comenzaban su descenso desde el mencionado promontorio hacia el ushnu. Una vez iniciado este recorrido, su descenso podía ser observado por quienes se encontraban congregados en el pequeño espacio público, quienes veían cómo los inkas emergían desde cerro y las rocas para dar comienzo a los rituales. Más importante aún es que, estando tras el afloramiento a $4839 \mathrm{msnm}$, los oficiantes podían entablar comunicación tanto con el cerro Meléndez como con los fértiles valles inferiores, intercedida esta última línea visual por un cuerpo de agua a los $4509 \mathrm{msnm}$.

Estas instancias de arribo hacia el complejo público/ceremonial de El Apunao creaban dos movilidades y experiencias distintas para dos grupos claramente demarcados. En esta dialéctica de la colonización, los representantes del Tawantinsuyu ocupaban el escenario principal desde el cual se conectaban simultáneamente con el público reunido en el espacio abierto y con las fuerzas naturales a fin de pedir, agradecer y reciprocar. Los inkas, como mediadores entre planos y conductores de las energías vitales, canalizaban el agua y la ofrecían a la tierra para regar los campos de cultivo de la región. Las libaciones realizadas por los auspiciantes rituales en el receptáculo de piedra podrían haber afianzado el rol de los inkas como mediadores y garantes en la provisión de agua para los campos agrícolas.

Por otro camino, aún no determinado en su totalidad, se llegaba a otro destacado sitio inka de altura: Uña Tambo (SSalCac 169, 2459'25.4”S, 66¹9'17.5”'W) (Figura 9). El asentamiento está emplazado a $4705 \mathrm{msnm}$ y se divide topográficamente en dos sectores en los que se destacan dos complejos arquitectónicos o kanchas de tipo inkaico. No sólo está emplazado en relación a tramos de camino, sino que se encuentra enfrentando la cara más destacada de una destacada formación geológica conocida como la Uña o la Aguja. Ésta sobresale visualmente por su forma de cuña cuando es vista desde los valles inferiores, por su color delantero rojo cuando es vista desde el sur y el suroeste, y su color trasero blanquecino en la punta cuando es vista desde el Norte. 


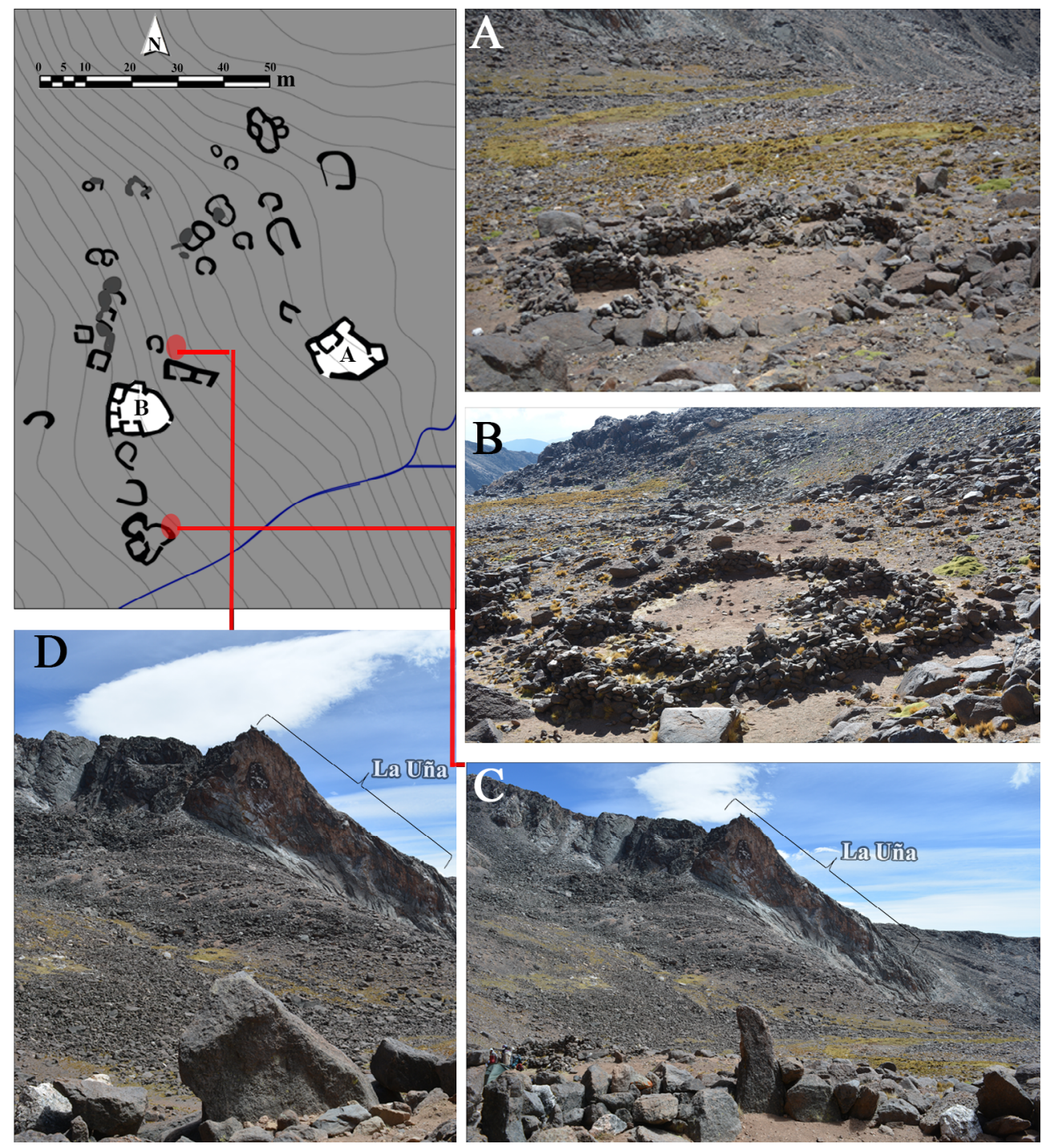

Figura 9. Uña Tambo y rasgos principales mencionados en el artículo;

kanchas inferior y superior (A y B), monolito (C), y posible roca eco (D) con la formación geológica conocida como «La Uña» o «La Aguja» de fondo.

Si bien en Uña Tambo no hay una plataforma tipo ushnu ni un espacio público central, sí posee al menos tres elementos que parecen haber marcado el ritmo ritual del lugar. Primero, las dos kanchas inka cuentan con un espacio de reunión de carácter cerrado y exclusivo que pudo haber sido empleado para congregar a parte de los peregrinos al sitio. Segundo, no lejos de la kancha superior se erige una roca que pareciera imitar a la Uña (ver Figura 9). Se debe señalar que este tipo de rocas que imitan geoformas son conocidas como «rocas eco» (Dean 2010: 55-56) y no sólo emplean la mímesis visual sino que además comparten una esencia común con aquello que encarnan. Similares ejemplos se han detectado en otros sitios inka como 
Machu Picchu o en sitios pre-inka como Tiwanaku (Kolata 1993: 109-143) donde también hay rocas acomodadas que imitan y conectan el lugar con rasgos especiales del paisaje circundante. Tercero, en el sector más elevado del sitio, empotrado en el muro de una estructura en un complejo arquitectónico de tres recintos, se emplazó un monolito de 1,3 m de alto. Esta roca, además de representar posiblemente otra roca eco, podría haber oficiado de sukanka (ver en Dean 2010: 53-56) dado que trabajos arqueoastronómicos previos demostraron que recibía los primeros rayos del sol en los equinoccios, sirviendo así como un marcador astronómico (Jacob et al. 2013; Moyano 2013: 202-208) (ver Figura 9).

Si El Apunao estuvo predominantemente conectado con el control simbólico del agua, es muy posible que Uña Tambo haya estado especialmente relacionado al culto al cerro Meléndez y a la Uña. Por su localización, debió ser una parada para los peregrinos que se dirigían a la cima del cerro Meléndez, así como un adoratorio de esta particular formación geológica denominada la Uña. En esta parada previa a la cumbre del Meléndez, los peregrinos pudieron haber realizado ofrendas al Apu y solicitar su permiso para ascender a la cima. No sería extraño pensar que los peregrinos también podrían haber utilizado aquella roca que emula a la Uña para ofrendar a distancia a este destacado y altamente visible rasgo de la geografía nor-calchaquí. Varios investigadores han argumentado que a fin de conectarse con ciertos cerros y geoformas, los pueblos andinos y los inkas construían miniaturas de ellos en lugares accesibles (Meddens 1994, 1997; Wachtel 2001). Estas miniaturas eran consideradas corporizaciones, extensiones y/o encarnaciones de estas wak'as y permitían homenajearlas a distancia sin tener que realizar peregrinajes o ascensos hacia ellas.

\section{Discusión y conclusiones}

Aquellos que concurrían a Cortaderas para participar de eventos rituales en la plaza de Cortaderas Bajo se encontraban con un lugar cuya topografía y arquitectura definían los movimientos y orientaban las vistas. La intención narrativa parece haber sido contextualizar la nueva realidad de los grupos locales y los representantes imperiales. Al acceder por el camino y adentrarse y acomodarse en la plaza, los cuerpos se veían orientados hacia la plataforma inkaica mientras se daba la espalda al abandonado pukara local. Los representantes del Tawantinsuyu, ubicados sobre la plataforma, podían dirigirse tanto a la audiencia congregada en la plaza como así también visualizar, evocar y convocar otros rasgos del paisaje, tal como el cerro Meléndez. En este contexto eran los inkas quienes, desde su posición privilegiada sobre el ushnu de Cortaderas Bajo, se relacionaban con este Apu regional a la vez que dejaban fuera de esta conexión a los visitantes locales que estuvieran en la plaza. La vocación narrativa del paisaje inkaico parece haber continuado cuando las personas se retiraban de la plaza. Al abandonar la plaza de Cortaderas Bajo y dirigirse hacia el sur, los visitantes nor-calcahquíes se encontraban con un paisaje que mostraba la intervención imperial en todo su esplendor. Vistas de Cortaderas Izquierda y Cortaderas Derecha, del camino inka o qhapac ñan y del intervenido cerro Meléndez se podían apreciar a la salida de Cortaderas Bajo (Acuto y Gifford 2007).

En Guitián, cercados por los altos muros y techos de los edificios y bloqueada la visión hacia el interior de las residencias inka, los participantes de las actividades ceremoniales llevadas a cabo en la plaza sólo podían apreciar lo que ocurría dentro de 
este espacio. A través del diseño espacial, los inkas aislaron a los participantes de las distracciones del entorno, concentrando la atención en los rituales que el Tawantinsuyu auspiciaba dentro de la plaza y particularmente en torno al ushnu. Al igual que en el caso de Cortaderas, el vínculo con el cerro Meléndez durante las ceremonias en la plaza debió estar reservado exclusivamente a el/los representantes del Tawantinsuyu ubicados sobre el ushnu. Nuevamente, los visitantes locales restablecían contacto con este Apu una vez que evacuaban la plaza y no antes.

Aquellos que llegaban peregrinando hasta El Apunao, accedían por un camino que desembocaba en aquel pequeño espacio abierto al pie de las plataformas y el receptáculo. Acomodados allí, la estrecha topografía del circo glaciar donde fue construido el sitio generaba un contrapunto entre dos vistas: 1) hacia la plataforma/ushnu y las performances rituales desarrolladas sobre ésta, y 2) en dirección este-sudeste, es decir, hacia la salida del sol y hacia los valles fértiles donde transcurría la cotidianeidad local. La primera vista probablemente haya estado reservada a los peregrinos locales. La segunda, reservada a los representantes del Tawantinsuyu y capaz de extenderse más allá del paisaje inmediato. Combinadas las vistas desde la plataforma ceremonial y desde aquel afloramiento a $4839 \mathrm{msnm}$, los inkas se presentaban en una posición privilegiada para mediar en la relación entre el Apu regional y los valles inferiores. En este esquema, el curso de agua que discurría por El Apunao para nutrir el río Las Arcas, proveedor de agua de una de las áreas agrícolas más ricas de la región, cobraba un protagonismo central. Desde el ushnu, los inkas se posicionaban como articuladores entre las entidades celestes, el cerro y los valles inferiores, entre el agua y los campos de cultivo, y entre los equinoccios y los ciclos agrícolas.

Para aquellos que peregrinaban a la cima del cerro Meléndez, Uña Tambo no sólo representaba un albergue para descansar antes de encarar el último tramo hasta la plataforma a $6013 \mathrm{msnm}$, sino que también debió haber representado una parada necesaria para ultimar preparativos y pedir permiso a este $A p u$ antes de acceder a lo que podría considerarse su mismísima cabeza (Ávila 1966: 65, 129 [ca. 1598] para referencias tempranas ${ }^{9}$; Bastien 1985 para referencias etnográficas). A estas alturas, fuera de la esfera de lo humano y de lo domesticado que representaban los valles fértiles y ya profundamente metidos en el territorio peligroso del Apu (Meddens et al. 2008: 342), los peregrinos debían tomar todas las medidas necesarias para homenajearlo y agasajarlo, garantizando así un ascenso tranquilo y seguro. En este esquema, las actividades de pagos y ofrendas debieron haber sido claves en Uña Tambo.

Como han discutido otros investigadores sobre el peregrinaje a los centros ceremoniales inka, a lo largo del derrotero se solía producir un proceso de estratificación que implicaba que no todos los peregrinos llegasen a las cercanías del objeto de culto, teniéndose que contentar con agasajarlo a la distancia (Bauer y Stanish 2001). Una vez en el asentamiento, como típicamente sucedía en los centros provinciales del Tawantinsuyu, el espacio separaba a los representantes inkaicos de los locales. Es posible que en los circunscritos patios de sus kanchas residenciales los inkas hayan realizado pagos y ofrendas al cerro Meléndez. Quizá incluso invitando a participar de estos contextos a algunos locales. Esto, por supuesto, no impedía que estos últimos también realizaran ofrendas y pedidos de permiso al Apu y a la Uña en otros lugares. Si bien el cerro Meléndez no era visto directamente desde este lugar, su

\footnotetext{
En otros lugares del manuscrito se hace referencia indirecta a la movilidad de las wak'as en forma de cerro o montaña y se hace clara alusión a extremidades y a la cabeza (Ávila 1966: 73, 133 [1598]).
} 
presencia posiblemente se hacía notar debido a que los peregrinos se encontraban en su área de influencia directa (Allen 2015). No sólo el Meléndez pudo haber sido objeto de ofrendas previas al ascenso final, sino que los que allí llegaban parecen haberse dedicado (al menos durante ciertas fechas del año) a celebrar la salida del sol en los equinoccios y estructurar así el calendario agrícola. También, a homenajear a una llamativa formación geológica fácilmente divisible desde varios asentamientos del valle.

Evidentemente, los inkas fueron conscientes del poder del espacio en la definición de interacciones, temporalidades, sentidos y experiencias corporales. En los casos estudiados, es claro cómo la topografía y la arquitectura construían e imponían ciertas narrativas materiales y definían la forma en que las personas circulaban y se posicionaban, orientando sus cuerpos y sus sentidos. En estos lugares, los inkas buscaron claramente privilegiar y comunicar ciertas relaciones e ideas. En este trabajo se constató el modo en que la forma y arquitectura de los espacios públicos y de los ushnus de los sitios inkaicos buscaban entablar contacto con rasgos específicos del paisaje circundante, convocando a las ceremonias a estas entidades no humanas sagradas que habitaban el paisaje animado andino. Especialmente, la disposición de las plataformas parece responder a una escenificación que, parados sobre ella y en todos los casos, trasciende la escala de sitio para proyectarse a elementos del paisaje incluyendo otros poblados locales e inka.

Agradecimientos: Los resultados expuestos en este trabajo fueron producto de trabajos de campo financiados por Heinz Grant for Latin American Archaeology, Wenner-Gren Foundation for Anthropological Research, International Collaborative Research Grant, y la National Geographic Society. Agradecemos a la comunidad Diaguita-Kallchakí por interesarse y participar activamente en discusiones y trabajos de campo, y por la hospitalidad y predisposición que han mostrado a lo largo de los años.

\section{Referencias}

Acuto, Félix A.

1999 «Paisaje y dominación: La constitución del espacio social en el Imperio Inka», en Sed non satiata. Teoría social en la arqueología latinoamericana contemporánea, Andrés Zarankin y Félix A. Acuto, eds., pp. 33-76. Buenos Aires: Ediciones del Tridente.

2004 «Landscapes of Ideology and Inequality: Experiencing Inka Domination». Tesis doctoral, State University of New York, Binghamton.

2005 «The Materiality of Inka Domination: Landscape, Spectacle, Memory, and Ancestors», en Global Archaeology Theory: Contextual Voices and Contemporary Thoughts, Pedro P. Funari, Andrés Zarankin y Emily Stovel, eds., pp. 211-235. Nueva York: Kluwer Academic/Plenum Publishers.

2010 «Living under the Imperial Thumb in the Northern Calchaquí Valley (Argentina)», en Distant Provinces in the Inka Empire: Toward a Deeper Understanding of Inka Imperialism, Michael Malpass y Sonia Alconini, eds., pp. 108-150. Iowa City: University of Iowa Press.

2011 «Encuentros coloniales, heterodoxia y ortodoxia en el valle Calchaquí Norte bajo el dominio inka». Estudios Atacameños, Arqueología y Antropología Surandinas 42: 5-32. 
Acuto, Félix A. y Chad GiFford

2007 «Lugar, arquitectura y narrativas de poder. Relaciones sociales y experiencia en los centros inkas del valle Calchaquí Norte». Arqueología Sudamericana 3 (2): 135161.

Acuto, Félix, Ezequiel GiLARdenghi y Marina Smith

2011 «Reenhebrando el pasado: hacia una epistemología de la materialidad». Boletín del Museo Chileno de Arte Precolombino 86 (2): 9-26.

Acuto, Félix A., Marisa Kergaravat y Claudia Amuedo

2011 «Experiencia de la muerte y la representación de las personas en las prácticas funerarias del valle calchaquí norte». Comechingonia 14: 23-54.

Acuto, Félix A., Andrés Troncoso y Alejandro Ferrari

2012 «Recognising Strategies for Conquered Territories: A Case Study from the Inka North Calchaqui Valley». Antiquity 86 (334): 1141-1154.

Allen, Catherine J.

2014 «Ushnus and Interiority», en Inca Sacred Space Landscape, Site and Symbol in the Andes, Frank Meddens, Katie Willis, Colin McEwan y Nicholas Branch, eds., pp. 71-77. Londres: Archetype Publications.

2015 «The Whole World Is Watching. New Perspectives on Andean Animism», en The Archaeology of Wak'as: Explorations of the Sacred in the Pre-Columbian Andes, Tamara Bray, ed., pp. 23-46. Boulder: University Press of Colorado.

AmBrosetTi, Juan Bautista

1907 «Exploraciones arqueológicas en la ciudad prehistórica de La Paya (Valle Calchaquí, Pcia. de Salta)». Revista de la Universidad de Buenos Aires 8: 5-534

Ataliva, Víctor H., Álvaro R. Martel, Carolina Somonte y Sara LóPez CAmPenY

2010 «Notas marginales desde el sitio incaico Nevados del Aconquija (Tucumán, Argentina)». Andes 21 (1): 161-186.

ÁvILA, Francisco.

1966 Dioses y hombres de Huarochirí [1598], traducido por J.M. Arguedas y con estudio bibliográfico de P. Duviols. Lima: Instituto de Estudios Peruanos.

Bastien, Joseph W.

1985 Mountain of the Condor: Metaphor and Ritual in an Andean Ayllu. Long Grove: Waveland Press.

BAUER, Brian

1992 The Development of the Inca State. Austin: University of Texas Press.

BAUER, Brian y Charles STANISH

2001 Ritual and Pilgrimage in the Ancient Andes. The Islands of the Sun and the Moon. Austin: University of Texas Press.

Ceruti, Constanza

2009 «Relevamiento arqueológico en el Nevado de Cachi: Cumbre Meléndez y Quebrada de la Hoyada (Provincia de Salta)», en Actas del VI Congreso Argentino de Americanistas, tomo 2, pp. 17-32. Buenos Aires: Sociedad Argentina de Americanistas.

D’altroy, Terence N. y Verónica WiLliams

1998 The 1997 Field Research of the Proyecto Arqueológico Calchaquí. Informe entregado a la Fundación Heinz, Pittsburgh. 
D’altroy, Terence, Ana María Lorandi, Veronica Williams, Milena Calderari, Christine Hastorf, Elizabeth Demarrais y Melissa Hagstrum.

2000 «Inka Rule in the Northern Calchaquí Valley, Argentina». Journal of Field Archaeo$\log 27$ (1): 1-26.

DeAn, Carolyn

2010 A Culture of Stone. Durham: Duke University Press.

2015 «Men Who Would Be Rocks: The Inka Wank`a», en The Archaeology of Wak'as: Explorations of the Sacred in the Pre-Columbian Andes, Tamara Bray, ed., pp. 239263. Boulder: University Press of Colorado.

FARRINGTON, Ian

2013 Cusco. Urbanism and Archaeology in the Inka World. Gainesville: University Press of Florida.

FARRINGTON, Ian y Julinho ZAPATA

2003 «Nuevos cánones de arquitectura inka: investigaciones en el sitio de TambokanchaTumibamba, Jaquijahuana, Cuzco». Boletín de Arqueología PUCP 7: 57-77.

FERRARI, Alejandro

2012 Espacialidad local e inka: aportes a partir un caso de estudio en el Valle Calchaquí Norte (Salta, Argentina). Tesis de Licenciatura, Facultad de Filosofía y Letras, Universidad de Buenos Aires.

2016 «Espacialidad local e inka en el Valle Calchaquí Norte (Salta, Argentina): Reevaluando el alcance de la intervención imperial en La Paya» Estudios Atacameños, Arqueología y Antropología Surandinas 53: 55-72.

Ferrari, Alejandro, Iván LeIBowicz, Joaquín Izaguirre y Félix ACUTo

2017 «Arquitectura y paisaje sonoro de un asentamiento inka en el Noroeste Argentino» Chungará 49 (3): 309-325.

Gil García, Francisco M.

2012 «La comunión de los cerros. Ritualidad y ordenamiento simbólico del paisaje en una comunidad del altiplano sur andino». Diálogo Andino, Revista de Historia, Geografia y Cultura Andina 39: 39-55.

GonzÁlez, Alberto Rex y Pío Pablo Díaz

1992 «Notas arqueológicas sobre la Casa Morada, La Paya, Pcia. de Salta». Estudios de Arqueología 5: 13-45.

HYSLOP, John

1984 The Inka Road System. Nueva York: Academic Press.

1990 Inka Settlement Planning. Austin: University of Texas Press.

JACOB, Cristian e Iván LEIBOwicz

2011 «Montañas sagradas en los confines imperiales. Nevado de Cachi, Salta-Argentina». Revista Haucaypata. Investigaciones arqueológicas del Tahuantinsuyo 2: 71-90.

2014 «Ceremonias en la tormenta. Ritual inka en el Nevado de Cachi». Estudios de Antropología-Historia, Nueva Serie 2: 27-48.

JACOB, Cristian, Ricardo Moyano, Félix ACUTO e Iván LeIBowicz

2011 «Quilca del cielo: Valle Calchaquí, Salta, Argentina». Boletín APAR 3 (10): 348-350.

JACOB, Cristian, Iván LeIBowicz, Félix Acuto y Ricardo Moyano

2013 «Paisaje ritual y marcadores astronómicos en el sitio Uña Tambo, Nevados de Cachi, Salta, Argentina». Arqueología y Sociedad 26: 291-302 
Kergaravat, Marisa y Claudia Amuedo

2012 «Procesos de cambio en las prácticas mortuorias de los contextos locales bajo el dominio incaico en el Valle Calchaquí Norte, Salta», en Entre pasados y presentes III. Estudios contemporáneos en ciencias antropológicas, N. Kuperszmit, T. Mármol, L. Mucciolo y M. Sacchi, comps., pp. 469-486. Buenos Aires: Mnemosyne.

KolatA, Alan L.

1993 The Tiwanaku: Portrait of an Andean Civilization. Oxford: Blackwell.

LANZA, Matilde M.

1996 «Grabados rupestres en el Valle Calchaquí: avances y perspectivas». Chungará 28 (1-2): 223-239.

2000 «Análisis estilístico del arte rupestre del Valle Calchaquí Norte, Salta», en Arte en las rocas. Arte rupestre, menhires y piedras de colores en Argentina, Mariana Podestá y María de Hoyos, eds., pp. 63-71. Buenos Aires: Sociedad Argentina de Antropología.

MedDENS, Frank

1994 «Mountains, Miniatures, Ancestors, and Fertility: The Meaning of Late Horizon Offerings in a Middle Horizon Structure in Peru». Bulletin of the Institute of Archaeology 31:127-150.

1997 «Function and Meaning of the Usnu in Late Horizon Perú». Tawantinsuyu 3: 4-14.

2015 «The Importance of Being Inka. Ushnu Platforms and their Place in the Andean Landscape», en The Archaeology of Wak'as: Explorations of the Sacred in the PreColumbian Andes», Tamara Bray, ed., pp. 239- 263. Boulder: University Press of Colorado.

Meddens, Frank, Nicholas Branch, Cirilo Vivanco, Naomi Riddiford y Rob KemP

2008 «High Altitude Ushnu Platforms in the Department of Ayacucho Perú, Structure, Ancestors and Animating Essence», en Pre-Columbian Landscapes of Creation and Origin, John E. Staller, ed., pp. 315-355. Nueva York: Springer.

MonteVerde, Luis R.

2010 «La configuración arquitectónica de los ushnus como espacios de libaciones y ofrendas líquidas durante el Tahuantinsuyo». Bulletin de l'Institut Français d'Études Andines 40 (1): 31-80.

MOORE, Jerry D.

1996 «The Archaeology of Plazas and the Proxemics of Ritual». American Anthropologist 98 (4): 789-802.

MOYANO, Ricardo

2013 La Luna como objeto de estudio antropológico: El ushnu y la predicción de eclipses en contextos incas del Collasuyu. Tesis Doctoral en Arqueología. Escuela Nacional de Antropología e Historia (ENAH). México.

2014 «Astronomical Observation on Inca Ushnus in Southern Andes», en Inca Sacred Space Landscape, Site and Symbol in the Andes, F. Meddens, K. Willis, C. McEwan y N. Branch, eds., pp. 187-196. Londres: Archetype Publications.

NiLES, Susan

1992 «Inca Architecture and Sacred Landscape», en The Ancient Americas: Art from Sacred Landscapes, Richard Townsend, ed., pp. 346-57. Chicago: The Art Institute of Chicago. 
Pino Matos, José Luis

2004 «El ushnu inka y la organización del espacio en los principales tampus de los Wamani de la sierra central del Chinchaysuyu». Chungará 36 (2): 303-311.

STALleR, John E.

2008 «Dimensions of Place: The Significance of Centers to the Development of Andean Civilization: An Exploration of the Ushnu Concept», en Pre-Columbian Landscapes of Creation and Origin, John E. Staller, ed., pp. 269-313. Nueva York: Springer.

VAN De Guchte, Maarten

1999 «The Inca Cognition of Landscape: Archaeology, Ethnohistory, and the Aesthetic of Alterity», en The Archaeologies of Landscapes: Contemporary Perspectives, Wendy Ashmore y Bernard Knapp, eds., pp. 149-168. Oxford: Blackwell.

VITRY, Christian

2008 El Nevado de Cachi. Río Cuarto: Palloni Ediciones.

WACHTEL, Nathan

2001 El regreso de los antepasados. Los indios urus de Bolivia, del siglo XX al XVI. México: Fondo de Cultura Económica.

WiLliams, Verónica

2004 «Poder estatal y cultura material en el Kollasuyu». Boletín de Arqueología PUCP 8: 209-246.

ZUIDEMA, Tom

1980 «El ushnu». Revista de la Universidad Complutense 28: 317-362. 